\title{
Missing in Action: Indigenous Knowledge Systems in Evaluation of Comprehensive Community Initiatives
}

\author{
Judy Gillespie \\ University of British Columbia \\ Jason Albert \\ First Nations University of Canada \\ Shelaine Grant \\ Island Health \\ Tanya Mackeigan
}

Indigenous Policy, Planning, and Community Development

\begin{abstract}
Comprehensive community initiatives (CCIs) coordinate social and structural change across multiple community sectors and represent promising approaches to complex social problems. Nowhere is this more relevant than for Indigenous children and families. However, strategies to evaluate initiatives to enhance Indigenous well-being must be meaningful to Indigenous communities. A review of literature regarding evaluation of CCIs identified various principles, case studies, methodologies, and methods grounded in Western ways of knowing and approaches to research. Research that engages with Indigenous-led comprehensive community initiatives is needed to enhance evaluation practices for CCIs that enables resurgence of Indigenous traditions and worldviews.
\end{abstract}

Keywords: Aboriginal, child welfare, community development, multisector collaboration, social change, systems, systems thinking

Résumé : Les initiatives communautaires intégrées assurent la coordination de changements sociaux et structurels dans plusieurs secteurs de la communauté et constituent des approches prometteuses pour résoudre des problèmes sociaux complexes. Elles sont particulièrement pertinentes pour les enfants et les familles autochtones. Il reste que les stratégies d'évaluation d'initiatives visant l'amélioration du bien-être des Autochtones doivent avoir un sens pour leurs communautés. Un examen des écrits sur l'évaluation des initiatives communautaires intégrées a cerné divers principes, études de cas, méthodologies et méthodes fondées sur les modes de connaissance et les approches en matière de recherche occidentales. Des recherches axées sur les initiatives communautaires intégrées gérées par des Autochtones doivent être menées pour améliorer les pratiques d'évaluation de ces initiatives d'une façon qui encourage la résurgence des traditions et des points de vue autochtones.

Corresponding author: Judy Gillespie, School of Social Work, University of British Columbia, Arts Building, 1147 Research Road, Kelowna, BC V1V 1V7; judy.gillespie@ubc.ca

(C) 2020 Canadian Journal of Program Evaluation / La Revue canadienne d'évaluation de programme 35.2 (Fall / Automne), 170-187 doi: 10.3138/cjpe.69099 
Mots clés : autochtone, protection de l'enfance, développement communautaire, collaboration multisectorielle, changement social, systèmes, théorie des systèmes

\section{CONTEXT FOR THE RESEARCH}

There is increasing evidence that complex social problems are best addressed through comprehensive community initiatives (CCIs): highly contextual, multisector, social change-focused collaborations that cross functional boundaries and departmental silos. They are grounded in and responsive to local conditions and local knowledge (Bradford, 2005; Kania \& Kramer, 2011; Torjman \& LevitenReid, 2003). Nowhere is this more relevant than with respect to the well-being of Indigenous children and families. Despite a lack of consistent measurement within and between various jurisdictions, Indigenous children and families are significantly overrepresented in statutory child-protection systems, a trend that is international in scope (Australian Institute of Health and Welfare, 2010; Bennet \& Auger, 2013; Delfabbro, Hirte, Rogers, \& Wilson, 2010; Public Health Agency of Canada, 2010; Thoburn, 2007; U.S. Department of Health and Human Services, 2009). Analysis of "pathways" to overrepresentation suggests multiple intersecting and interrelated factors (Carter, 2010; Lavergne, Dufour, Trocmé, \& Larrivée, 2008; Sinha et al., 2011; Trocmé, Knoke, \& Blackstock, 2004). In Canada, as in other countries with a history of colonization, Indigenous peoples are overrepresented in almost all negative measures of well-being. They are proportionally more likely to suffer mental and physical health problems, be unemployed, live in poverty, experience interpersonal violence, have poor housing, and drop out of school. Indigenous peoples also constitute proportionally higher percentages in juvenile justice and adult prison populations. These issues are linked to the legacy of colonization and systems of residential schooling imposed on Canada's Indigenous peoples and directly affect the well-being of Indigenous children and families. Their overrepresentation in statutory child-protection systems is thus a complex social problem that child welfare systems cannot address in isolation. Multisector collaboration is needed to address social and structural factors and promote and enhance the resilience embedded in Indigenous cultures and traditions (Blackstock \& Trocmé, 2005; Gillespie, Supernault, \& Abel, 2014).

Yet CCIs are difficult to enable and even more difficult to sustain (Kania \& Kramer, 2011; Provan, Veazie, Staten, \& Teufel-Shone, 2005). In part this is due to the challenge of evaluating their impacts; CCIs are not amenable to traditional methods of evaluation (Auspos \& Kubisch, 2012; Cabaj, 2014; Kania \& Kramer, 2011). Over 20 years ago, the Roundtable on Comprehensive Community Initiatives for Children and Families struck a Steering Committee on Evaluation to address the lack of fit between CCIs and traditional methods of evaluation (Connell, Kubisch, Schorr, \& Weiss, 1995). Since then, development of evaluation methods for CCIs has proceeded across a range of social science disciplines, governments, and NGOs, with an array of alternative methods and approaches (see, for example, Brown, 2010; Cabaj, 2014; Farrow \& Schorr, 2011; Fiester, 2011; Foster-Fishman, Nowell, \& Yang, 2007; Kelly, 2010; Patton, 2010; Provan et al., 2005). 
We are researchers, professors, and former social work students who share an interest in child and family well-being and the role of Indigenous ways of knowing. Judy Gillespie is a non-Indigenous researcher with a 12-year history of collaborative research with an Indigenous-led CCI in northwestern Alberta (Gillespie et al., 2014). Jason Albert is of Cree descent, originally from Sweetgrass First Nation, but currently registered with Muskeg Lake Cree Nation. His research examines Indigenous social work administration, with a particular focus on Indigenous leadership, management, and organizations. Shelaine Grant and Tanya MacKeigan are former students who worked as research assistants with Drs. Gillespie and Albert while completing their graduate degrees. Shelaine is a nonIndigenous clinical social worker currently working in health care. Her interests include community views and experiences of CCIs. Tanya is a non-Indigenous policy and community development social worker working as a community planner on an Okanagan Indigenous-focused mental well-being team. Her research interests are rooted in community partnerships and community-driven social justice pursuits.

Several years ago, our interest in multisector CCIs to enhance Indigenous well-being and address the overrepresentation of Indigenous children and families in Canada's child welfare systems led us to a review and synthesis of this literature. We were hoping to identify promising approaches to evaluate the impacts of CCIs in promoting the well-being of children and families that acknowledged and respected the role of Indigenous knowledge systems in such evaluation. The literature review and synthesis were guided by the following question: What are the most promising approaches to evaluate community-change impacts of comprehensive community initiatives (CCIs) in promoting Aboriginal child and family well-being and how might Indigenous ways of knowing and approaches to research assist in such evaluation?

This article presents findings from our literature review and synthesis, noting that our research question was not answered in our original review. Culturally appropriate evaluation strategies for Indigenous-led CCIs working to enhance the well-being of Indigenous children and families remain an important area for further development. In this article we present seven principles for enhancing the relevance of evaluation with and for Indigenous peoples. These principles are grounded in literature on Indigenous research methodologies and program evaluation and can be used to guide future research with Indigenous-led CCIs.

\section{EVALUATION AND INDIGENOUS KNOWLEDGE SYSTEMS}

Indigenous well-being entails both decolonization and reconciliation, or resistance and resurgence (CCPA Manitoba, 2018). Resistance speaks to the ways in which Indigenous peoples, in Canada and internationally, are confronting and refusing colonial and neo-colonial practices that oppress, exploit, and marginalize them and their cultures. Research is directly implicated in these neo-colonial practices (Brant Castellano, 2004; CCPA Manitoba, 2018; LaFrance \& Nichols, 2010; Tuhiwai-Smith, 2012). Too often, neo-colonial research practices have framed 
Indigenous peoples as a "problem" to be investigated, with little or no attention to broader contexts and the myth of "objective" research has resulted in the perpetuation of negative stereotypes of Indigenous peoples, their cultures, beliefs, and traditions (Tuhiwai-Smith, 2012). Western research has also often resulted in the intellectual theft of Indigenous knowledge, as information that is shared by Indigenous participants becomes "owned" by others, with Indigenous peoples denied access (Brant Castellano, 2004). Along with all of the above, Indigenous ways of knowing have been viewed as inferior, "unscientific," or lacking rigour (Kovach, 2009; Tuhiwai-Smith, 2012; Wilson, 2008):

In the past, Aboriginal people have not been consulted about what information should be collected, who should gather that information, who should maintain it, and who should have access to it. The information gathered may or may not have been relevant to the questions, priorities and concerns of Aboriginal peoples. Because data gathering has frequently been imposed by outside authorities, it has met with resistance in many quarters. (Royal Commission on Aboriginal Peoples, 1997, p. 498)

Canada's Assembly of First Nations (AFN) has adopted OCAP ${ }^{\circledast}$ principles for research with First Nations, ${ }^{1}$ which refers to ownership of all information collected in the research process, control over all research processes at all stages of the research, full access to the research including decision making regarding access by others; and possession, actual physical control of the data. These principles are fundamentally tied to First Nations self-determination and the preservation and development of their cultures.

Resurgence involves reclamation of Indigenous knowledge systems and engagement in and with practices that honor and reflect these worldviews. Resurgence requires space, recognition, and respect for this reclamation, and it is this that is the true path to reconciliation (CCAP, 2018). Research approaches must honour and reflect Indigenous worldviews and knowledge systems. These encompass Indigenous ontologies (ways of being), Indigenous epistemologies (ways of knowing), and Indigenous methods (ways of doing) (Martin \& Mirraboopa, 2009). Indigenous research methodologies do not encompass a consistent generalized framework through which research activities are defined and planned. Instead, as Tuhiwai-Smith (2001, p. 15) notes, "Indigenous methodologies tend to approach [local] cultural protocols, values and behaviours as an integral part of methodology." Thus, research is organic, emerging from and guided by practices and protocols grounded in specific places, and cultural traditions and practices of those places (Kovach, 2009). Shawn Wilson (2008) suggests that Indigenous methodologies encompass the 3Rs of respect, reciprocity, and relationality. These principles go beyond respecting the knowledge that each individual has to offer to the research process, to encompass respect for the community as a whole, its values, traditions, and beliefs, and its ideas and aspirations; the research must be framed within these. As Wilson notes, this requires "deep listening and hearing with more than the ears" (p. 59). And while each participant is viewed as equally important, there is particular respect for the knowledge and insight of Elders. 
Respect also requires honesty and transparency by all participants in the research process. Reciprocity requires a mutual exchange of benefits; those in the role of researcher both give to and receive from the community and its members. Benefits should not flow only one way. Relationality encompasses accountability; researchers are not only accountable to the immediate community or participants but also are engaged and accountable to a much broader constituency. Wilson suggests that responsibility and accountability extend to the relationship the researcher has with the world around him or her; it requires researchers to be accountable to "all my relations" - past, present, and future; land, plants, animals, and human. Ultimately, research must honour and respect the interrelatedness of researcher and researched.

Like research, evaluation has been viewed as highly problematic by many Indigenous peoples, encompassing many of the problems identified above. This includes the imposition of external evaluations on Indigenous communities with little to no attention to culturally safe or respectful practices, and with Indigenous participants often denied control over or even access to evaluation results (CCPA Manitoba, 2018; Kawakami, Aton, Cram, Lai, \& Porima, 2007; LaFrance \& Nichols, 2010). Indigenous writers have noted that the term evaluation is not easily translated into Indigenous languages (CCPA Manitoba, 2018; LaFrance \& Nichols, 2010). Determining individual, community, or program worth through externally imposed standards or "indicators" of what the individual, community, or program "should have" achieved does not resonate with Indigenous worldviews that view evaluation as a process of reflection and contemplation (CCPA Manitoba, 2018; Kawakami et al., 2007; LaFrance \& Nichols, 2010). Thus, while necessary, the identification of promising approaches in evaluation of CCIs with and for Indigenous participants has been a challenging exercise, and our original research question remains unanswered. Grounded in Indigenous research and evaluation methodologies, we propose seven principles for examining evaluation of CCIs to enhance Indigenous well-being.

\section{The centrality of context}

Among Indigenous cultures, the land is a living, and sacred, presence and is central to individual and collective identity (LaFrance \& Nichols, 2010). Consequently, evaluation requires a deep understanding of and engagement with contextual place-based aspects, including the history of a place and the meanings and identities it holds for the Indigenous peoples who have traditionally inhabited the land (CCPA Manitoba, 2018). In the words of Kawakami et al. (2007, p. 332), "evaluation must be viewed and implemented as a holistic and contextualized experience with respect to a specific place, time, community, and history." In this way, evaluation itself becomes part of context (LaFrance \& Nichols, 2010).

\section{Indigenous community engagement and control}

Promising approaches should engage communities in the planning and implementation of evaluation. Research should be relevant and beneficial to the 
community and should support the development of local capacity. Throughout the process, evaluators must ask how the needs of the community will remain central to the evaluation (CCPA Manitoba, 2018). LaFrance and Nichols (2010) note the purpose and goals of a project or initiative should be determined by the community, based on its priorities and needs. Evaluation begins with identifying questions that are important to the community. Communities should also have full access to findings and results (Chandna et al., 2019). Kawakami and colleagues (2007) assert that findings should be communicated first to the community, while the Manitoba ILC suggests that the community not only should have access to findings but also should be in control of processes through which findings are shared with broader audiences (CCPA Manitoba, 2018).

\section{Elders and Knowledge Keepers}

Another theme in the literature was the critical role of consultation with Elders and Knowledge Keepers in designing and conducting evaluation. The ILC suggests that consultation with and advice from Elders can enhance contextual knowledge and adherence to cultural protocols and practices (CCPA Manitoba, 2018). Elders and Knowledge Keepers can also ensure the incorporation of ceremony into evaluation practices (Kawakami et al., 2007; LaFrance \& Nichols, 2010).

\section{Evaluation as relationship}

As noted above, a core Indigenous value is that of relationship (Wilson, 2008). Relationships take time to develop and are built on respect and reciprocity. In the practice of evaluation, relationships encompass the relationship between evaluator and the community, organization(s), the issues being addressed, participants and their families, the land, and past and future generations. It is through relationships that knowledge develops. What relationships does the evaluator have with each of these groups? How will positive and reciprocal relationships be built? Accountability is a core aspect of relationship and concerns how we respect and maintain balance in our relationships and honour the responsibility that comes with fulfilling our relationships and answering to our relations with the world around us (CCPA Manitoba, 2018; Kawakami et al., 2007).

\section{Evaluation as reflection}

As noted above, the term evaluation does not directly translate into any Indigenous language. Determining individual, community, or program worth through externally imposed standards or "indicators" of what the individual, community, or program "should have" achieved within a specified timeframe does not resonate with Indigenous worldviews (LaFrance \& Nichols, 2010). What comes closest to "evaluation" is a deeply reflective and contemplative process of "looking back and seeing what worked, what didn't, and then determining the path ahead" (CCPA Manitoba, 2018, p. 3). Evaluation thus involves taking stock and reflecting in order to move forward. The emphasis is on creating space for learning and growth, 
for reflecting on what has worked, celebrating the journey, taking that learning into the future in order to live well within a particular place. Rather than conveying judgement, "evaluation should be viewed as an opportunity for learning" (LaFrance \& Nichols, 2010, p. 18). From a community perspective, evaluation is about reflecting on the quality of life that the community cares about and the best way to contribute to that (Kawakami et al., 2007). This is a deeply deliberative and dialogical process that is not only or even primarily about content but is about communicating in respectful ways, ensuring that all voices are heard, considering the long-term consequences of immediate actions or decisions, and being open to guidance from the Creator and ancestors (LaFrance \& Nichols, 2010).

\section{Evaluation as empowerment}

Above it was noted that community needs and priorities should be central to the evaluation process with communities engaged in planning and implementation of evaluation and having full access to, and even control over, findings and dissemination (CCPA Manitoba, 2018; Chandna et al., 2019; Kawakami et al., 2007; LaFrance \& Nichols, 2010). Also identified was the need for evaluation practices to enable resistance to the imposition of Western ways of knowing and constructs of "value" and to contribute to the resurgence of traditional Indigenous values, knowledge, and practices (CCPA Manitoba, 2018).

\section{Evaluation as ceremony}

Ceremony is a critical component at various points in the deeply reflective processes that constitute Indigenous ways of knowing (CCPA Manitoba, 2018; Kawakami et al., 2007; LaFrance \& Nichols, 2010). This reflects Wilson's (2008) observation that research is ceremony. It is through ceremony that connections are made with the spiritual world that enable stronger relationships and deeper understanding. Ceremonies can include land-based ceremonies and ceremonies incorporating fire, drumming, and singing (CCPA Manitoba, 2018). Talking circles are traditional and ceremonial means of learning, co-constructing knowledge, and establishing or deepening relationships. They have been used in Indigenous societies for generations to promote group interaction. On a symbolic level they have been used to convey teachings and promote the development of individual and community values, and on a practical level they have been used as a structure for ceremonies, discussions, and problem solving (Kovach, 2009).

\section{RESEARCH METHODS}

Our literature review began with two members of the research team generating a list of search terms in conjunction with a librarian who provided training in literature review strategies. A decision was made to include both peer-reviewed and grey literature. It was felt that the grey literature might offer expertise and insights that might not appear in academic databases. Databases included Google Scholar, AgeLine, Campbell Collaboration, CINAHL (Cumulative Index to Nursing and 
Allied Health Literature), Cochrane Database of Systematic Reviews (CDSR), ERIC, Indigenous Peoples North America, Indigenous Studies Portal, International des Libris, LGBT Life, MEDLINE (Ovid), MEDLINE (EBSCO), Native Health Database, PAIS Archive, PAIS International, PsychEXTRA, PsychInfo, PubMed, Social Work Abstracts, Social Services Abstracts, and Sociological Abstracts. Searches of academic databases utilized Boolean search strategies with various combinations and permutations of the following terms: Aboriginal, Indigenous, First Nations, Metis, child, adolescents, families, child welfare, social innovation, community initiative, comprehensive community initiative, community change, community development, community based coalitions, collective impact, evaluation, program evaluation, evaluation models, and impact reports. The strategy used for Google Scholar was controlled through a narrowing technique that utilized full phrases as opposed to key words. For example, during the first Google Scholar search, the actual research question was used and yielded eleven results. With both databases, a snowball approach was utilized; relevant material found through the searches was examined for additional material for review. No additional articles were found through this process.

Selection of literature was based on criteria that encompassed all of the following (see Figure 1 for the selection process):

- $\quad$ availability of a full-text version;

- focus on community or multi-level intervention or change strategies as opposed to individual intervention;

- focus on initiatives to enhance child and/or family well-being (with two exceptions-see case studies below);

- focus on impacts or outcomes of community change efforts;

- literature focusing solely on methods (no discussion of broader methodology) excluded;

- literature that described only collaborative practice as opposed to evaluation principles or methodologies excluded;

- literature that focused solely on evaluating conditions for collaboration excluded.

\section{FINDINGS}

\section{Case studies}

The literature review captured 18 case studies, most of which showcased evaluation methodologies, along with a variety of methods and tools for data collection and analysis. All of the case studies were of initiatives that included objectives of social and/or systems changes within specific communities. The majority $(n=12)$ were case studies of American initiatives, while some were case studies of Canadian initiatives $(n=5)$ and one was a case study of an Australian initiative. All but two focused on child and/or family well-being. The two case studies that did not focus specifically on evaluation of changes in child and/or family well-being were 
Stage 1: Identification of relevant literature

Seventy-nine documents were selected for initial review, forty-seven from academic databases, thirty-two from grey literature searches.

Stage 2: Initial review (79 documents)

Review of abstracts and/or methods sections of the documents resulted in exclusion of forty-one documents.

Stage 3: Analysis and Coding (38 Documents)

Analysis and thematic coding resulted in exlusion of four additional documents; three that did not meet inclusion criteria and one that was a duplicate of an article with a different title.

Four documents excluded.

Stage 4: Final Analysis and Knowledge Synthesis (34 Documents)

Figure 1. Selection of literature for synthesis 
included because of their specific focus on community change to enhance Aboriginal well-being. The first involved an off-reserve American Indian community (Blair, Busain, \& Tucker, 2015), while the second involved an urban Aboriginal initiative in Canada (Bradford \& Chouinard, 2009).

\section{Debates in evaluation of $\mathrm{CCls}$}

While all the literature emphasized the importance of evaluation and stressed the need for evaluation to be built in to CCIs from the beginning, there were numerous debates. One debate concerned the purpose and timeframe for evaluation. Summative evaluation is used as an accountability and future funding tool as well as for measuring outcomes and establishing evidence for policy or program development (Bradford \& Chouinard, 2009). The focus is on establishing valid generalizable associations between specific outcomes and specific services, programs, or policies. Therefore, the appropriate timeframe for evaluation is typically viewed as at or near the close of an initiative. However, the complex problems addressed by CCIs require sustained efforts that cut across single services, programs, or policies (Kania \& Kramer, 2011). Thus there were arguments that the primary purpose of evaluation of CCIs should be developmental, enabling monitoring and improvement of local efforts throughout the initiative (Kaufman et al., 2006). An additional argument suggested that the primary purpose of evaluation of CCIs should be empowerment and promotion of social justice, with evaluation serving an explicit purpose of transforming power relationships and serving the needs of the most marginalized (Cook, 2015).

A second debate concerned issues of relevance and credibility. Questions were raised regarding relevance of findings for whom: participants in community change initiatives, funders, policy makers, marginalized and disenfranchised community members? And credible to whom: participants, funders, academics? Who determines relevance and credibility, and what are the appropriate criteria for such determinations? (Abboud \& Claussen, 2016; Amed, Shea, Pinkney, Wharf Higgins, \& Naylor, 2016; Cabaj, 2014; Cook, 2015; Coombe, 2012; Fiester, 2011; Kania \& Kramer, 2011)

A related debate concerned scientific rigour. Developmental methodologies view internal validity as key to enabling contextual learning, connecting efforts to outcomes within specific contexts (Bradford \& Chouinard, 2009). However, the importance of external validity to aid in broader learning and policy development was evident in the promotion of generalizable approaches to the evaluation of CCIs (Komro, Flay, Biglan, \& Wagenaar, 2016; Lee \& Chavis, 2012). And while there appear to be efforts to bridge the two, there are arguments that they are largely incommensurate and should remain separate goals and strategies (Coffman, 2007).

A fourth debate concerned contextual sensitivity. Issues such as poverty, child abuse/neglect, homelessness, or addictions are present in many communities. However, they are mediated by and within specific place-based factors and interactions. Forms and processes of multisector collaboration often develop within 
communities with residents who both understand these contextual factors and have knowledge of place-specific resources and strategic actions. Some viewed these contextual aspects as critical components in evaluation (Kingsley, Coulton, \& Pettit, 2014). Other perspectives viewed contextual issues as impediments to generalizability and focused on control over, as opposed to understanding of, such issues (Amed et al., 2016; Farrow \& Schorr, 2011).

A fifth debate concerned the nature and goals of participation. In service of accountability, performance management, and/or establishment of evidence, evaluation is seen as best conducted by an "objective outsider" utilizing methods viewed as scientifically credible (Komro et al., 2016; Lee \& Chavis, 2012). Beyond completing surveys, or participating in semi-structured interviews or focus groups, stakeholder participation is often fairly circumscribed. However, others suggested that the primacy of contextual understanding, long-term learning and adaptation in evaluation of CCIs means that stakeholder participation is essential (Sridharan, Campbell, \& Zinzow, 2006). For evaluation methodologies that sought empowerment of marginalized community members, participation encompassed control over goals and measures of change.

The final debate concerned appropriate measures of change. While there was general interest in measuring social and systemic change, a wide range of approaches to measuring such change were identified. At the centre of these debates were questions of validity and scientific rigour (Lee \& Chavis, 2012).

\section{Evaluation methodologies}

Three methodological categories emerged: developmental, generalizable, and participatory. Developmental methodologies are designed to facilitate internal learning, growth, and adaptation for those involved in CCIs. Dominant within developmental approaches are "Theory of Change" (TOC) (Archibald, Sharrock, Buckley, \& Cook, 2016; Blamey \& Mackenzie, 2007; Coffman, 2007; FosterFishman \& Watson, 2012; Kubisch, Auspos, Brown, Buck, \& Dewar, 2011; Rogers, 2008). Realistic evaluation (Blamey \& Mackenzie, 2007), logic modelling (Hill \& Thies, 2010; Kaufman et al., 2006), outcome harvesting (Abboud \& Claussen, 2016), and timeline of impact (Sridharan et al., 2006) all share the goals of facilitating internal learning, adaptation, and growth for those engaged in CCIs and are closely associated with and intended to extend or complement TOC.

Generalizable methodologies focus on scientifically rigorous evaluation of complex community change initiatives that enhance their relevance for policy makers and/or funders to extend to other contexts (Amed et al., 2016; Komro et al., 2016; Lee \& Chavis, 2012; Peters et al., 2016). Stepped Wedge Cluster Random Control Trials, longitudinal studies with standardized continuous measurement, interrupted time-series designs, multiple baseline designs, and cost-benefit analysis were all identified as scientifically rigorous evaluation strategies for CCIs utilizing a range of quantitative data from cluster detection to socio-economic indicators, asset mapping, and spatial patterning, as well as qualitative data through 
questionnaires and semi-structured interviews (Kingsley et al., 2014; Komro et al., 2016). Cross-case methodology is purported to offer a scientifically rigorous methodology that merges strategies for contextual learning and adaptation with strategies for generalizable knowledge (Lee \& Chavis, 2012).

Participatory evaluation (PE) methodologies involve community members in understanding and improving CCI social change efforts (Coombe, 2012). Those with a stake in the change are in control of evaluation design, data collection, and analysis as well as dissemination and knowledge mobilization. External evaluators act as resources, allies, coaches, facilitators, and advocates to and for community members, building capacity, assisting with planning, organizational development, and action (Cook, 2015). Professional and academic evaluators can also utilize their expertise and connections to assist in translating findings into policy change or funding opportunities. In empowerment evaluation, evaluation serves an explicit purpose of transforming power relationships and serving the needs of the most marginalized. In some participatory approaches, participation of and control by marginalized and disenfranchised community members is a primary means of achieving change (Cook, 2015).

A wide range of methods and tools were identified throughout this literature review to aid in measuring community characteristics and indicators of change. Some were shared within the documents themselves, while others were identified as available for purchase.

\section{DISCUSSION AND CONCLUSION}

The first part of our research question asked, what are the most promising approaches to evaluate community change impacts of comprehensive community initiatives (CCIs) in promoting Aboriginal child and family well-being? Developmental approaches, with their emphasis on contextual knowledge and processes of reflection, learning, and adaptation resonate with the importance within Indigenous worldviews of looking back and seeing what worked as well as what didn't and determining the best path forward. However, TOC methodologies and approaches intended to enhance them are grounded in Western ways of knowing and approaches to time and place. While acknowledging the importance of context, developmental approaches do not call for the deep, historically grounded, place-based understanding and engagement that are central to Indigenous ways of knowing. Also, while developmental approaches emphasize community engagement, learning, and growth, this is not the deeply relational, contemplative, reflective, and dialogical approaches that characterize Indigenous knowledge systems. In addition, acting to "change" one's community to achieve pre-determined goals is different from Indigenous values of learning to live well within one's community based on reflection and dialogue. Finally, the spiritual guidance of Elders and Knowledge Keepers and the incorporation of ceremony are not present in developmental approaches to the evaluation of community change initiatives. 
Participatory methodologies also offer some promising aspects. Goals of community relevance, participation, and control resonate with $\mathrm{OCAP}^{\circledast}$ principles of ownership and control, while empowerment approaches directly fit with Indigenous goals of resistance and resurgence and the principle of evaluation as empowerment. However, within this literature, participatory methodologies were also grounded in Western worldviews and ways of knowing. Missing was any discussion of the importance of ceremony or spiritual guidance through Elders and Knowledge Keepers. While participatory methodologies, with their emphasis on community control, may be more able to embrace these core aspects of Indigenous approaches to evaluation, these would need to be explicitly addressed in the methodology.

The second part of our research question asked, how might Indigenous ways of knowing and principles for research assist in evaluation community change impacts of comprehensive community initiatives (CCIs) in promoting Aboriginal child and family well-being? Despite the relevance of CCIs to the well-being of Indigenous children and families, not only was there a notable absence of Indigenous knowledge in evaluation of CCIs to enhance child and family well-being, but there was also no discussion of the need for such knowledge.

Processes of truth and reconciliation have begun, first with the 1997 Report of the Royal Commission on Aboriginal Peoples, followed by the final report of the Truth and Reconciliation Commission of Canada in 2015. These processes not only acknowledge the traumatic legacy of colonial practices for Aboriginal health, education, employment, justice, child welfare, and more, but also illustrate how complex and inextricably intertwined these issues are. However, without changes on multiple fronts, we are unlikely to see significant or lasting changes on any. Community initiatives to address changes on multiple levels are critical to address Indigenous child and family well-being; however, advancing such initiatives requires methodologies to evaluate their impacts and outcomes. These must be meaningful to Indigenous peoples and reflect Indigenous worldviews and ways of knowing. There has been significant development of methodologies to evaluate CCIs, and both developmental and participatory approaches hold some promise. Yet these remain grounded in Western ways of knowing and do not reflect culturally relevant and respectful approaches for Indigenous peoples. Indigenous knowledge is missing in action in the evaluation of CCIs. Knowledge is needed regarding culturally relevant and respectful evaluation of CCIs that facilitates resistance to colonial and neo-colonial evaluation practices and enables resurgence of Indigenous traditions and worldviews. Such knowledge must be developed in conjunction with Indigenous participants in CCIs intended to enhance Indigenous child and family well-being.

\section{ACKNOWLEDGMENTS}

This research was supported by funding from the Social Sciences and Humanities Research Council of Canada. 


\section{NOTE}

$1 \mathrm{OCAP}^{\circledast}$ is a registered trademark of the First Nations Information Governance Centre available at http://www.FNIGC.ca/OCAP.

\section{REFERENCES}

Abboud, R., \& Claussen, C. (2016). The use of Outcome Harvesting in learning-oriented and collaborative inquiry approaches to evaluation: An example from Calgary, Alberta. Evaluation and Program Planning, 59, 47-54. https://doi.org/10.1016/j.evalprog plan.2016.08.005. Medline:27591484

Amed, S., Shea, S., Pinkney, S., Wharf Higgins, J., \& Naylor, P. J. (2016). Wayfinding the live 5-2-1-0 initiative: At the intersection between systems thinking and communitybased childhood obesity prevention. International Journal of Environmental Research and Public Health, 13(6), 614-630. https://doi.org/10.3390/ijerph13060614. Medline: 27338432

Archibald, T., Sharrock, G., Buckley, J., \& Cook, N. (2016). Assumptions, conjectures, and other miracles: The application of evaluative thinking to theory of change models in community development. Evaluation and Program Planning, 59, 119-127. https://doi. org/10.1016/j.evalprogplan.2016.05.015. Medline:27324286

Auspos, P., \& Kubisch, A. C. (2012). Performance management in complex, place-based work: What it is, what it isn't, and why it matters. Washington, DC: The Aspen Institute. Retrieved from http://www.aspeninstitute.org/sites/default/files/content/images/ rcc/Aspen_Performance_Management.pdf

Australian Institute of Health and Welfare. (2010). Child Protection Australia 2008-09. Retrieved from https:/www.aihw.gov.au/getmedia/b0df902e-0df3-43fd-a9f32679cf753f91/10859.20100901.pdf.aspx

Bennett, M., \& Auger, A. (2013). First Nations and non-Aboriginal children in child protection services. Prince George, BC: National Collaborating Centre for Aboriginal Health. Retrieved from http://www.nccah-ccnsa.ca/Publications/Lists/Publications/ Attachments/7/protective_services_EN_web.pdf

Blackstock, C., \& Trocmé, N. (2005). Community-based child welfare for Aboriginal children: Supporting resilience through structural change. In M. Ungar (Ed.), Handbook for working with children and youth: Pathways to resilience across cultures and contexts (pp. 105-120). Thousand Oaks, CA: Sage.

Blair, E., Busain, L. J., \& Tucker, P. (2015). Pathways to opportunity: Applying the principles of an effective, Indigenous comprehensive community initiative toward a thriving community. Retrieved from https://conservancy.umn.edu/bitstream/handle/ 11299/173965/Blair_Busian_Tucker-Pathways\%20to\%20Opportunity.pdf?sequence= 1\&isAllowed $=\mathrm{y}$

Blamey, A., \& Mackenzie, M. (2007). Theories of change and realistic evaluation: Peas in a pod or apples and oranges? Evaluation, 13(4), 439-455. https://doi. org/10.1177/1356389007082129

Bradford, N. (2005). Place-based public policy: Towards a new urban and community agenda for Canada. Family Network Research Report F51. Ottawa, ON: Canadian Policy 
Research Networks. Retrieved from http://neighbourhoodchange.ca/wp-content/ uploads//2011/06/Bradford-2005-Place-based-public-policy-agenda.pdf

Bradford, N., \& Chouinard, J. A. (2009). Learning through evaluation? Reflections on two federal community-building initiatives. Canadian Journal of Program Evaluation, 24(1), 51-77.

Brant Castellano, M. (2004). Ethics of Aboriginal research. International Journal of Indigenous Health, 1(1), 98-114.

Brown, P. (2010). Evaluating and learning from community change. In A. Kubisch, P. Auspos, P. Brown, \& T. Dewar (Eds.), Voices from the field III: Lessons and challenges from two decades of community change efforts (pp. 95-105). Washington, DC: The Aspen Institute.

Cabaj, M. (2014). Evaluating collective impact: Five simple rules. The Philanthropist, 26(1), 109-124. Retrieved from https://www.tamarackcommunity.ca/hubfs/Resources/ Publications/Evaluating\%20Collective\%20Impact\%205\%20Simple\%20Rules.pdf

Canadian Centre for Policy Alternatives (CCPA) Manitoba. (2018). Na-gah mo Waabishkizi Ojijaak Bimise Keetwaatino: Singing white crane flying north: Gathering a bundle for Indigenous evaluation. Winnipeg, MB. Retrieved from https://www.policyalternatives. ca/publications/reports/na-gah-mo-waasbishkizi-ojijaak-bimise-keetwaatino-singingwhite-crane-flying

Carter, V. (2010). Factors predicting placement of urban American Indian/Alaskan Natives into out-of-home care. Children and Youth Services Review, 32(5), 657-663. https:// doi.org/10.1016/j.childyouth.2009.12.013

Chandna, K., Vine, M. M., Snelling, S., Harris, R., Smylie, J., \& Manson, H. (2019). Principles, approaches, and methods for evaluation in indigenous contexts: A grey literature scoping review. Canadian Journal of Program Evaluation, 34(1), 21-47. https://doi. org/10.3138/cjpe.43050

Coffman, J. (2007). A framework for evaluating systems initiatives. Build Strong Foundations for Our Youngest Children. Retrieved from http://pathways.nccp.org/assets/ pdf/Coffman2007.pdf

Connell, W., Kubisch, A., Schorr, L., \& Weiss, C. (1995). New approaches to evaluating community initiatives: Concepts, methods, and contexts. New York, NY: The Aspen Institute.

Cook, J. R. (2015). Using evaluation to effect social change: Looking through a community psychology lens. American Journal of Evaluation, 36(1), 107-117. https://doi. org/10.1177/1098214014558504

Coombe, C. (2012). Participatory approaches to evaluating community organizing and coalition building. In M. Minkler (Ed.), Community organizing and community building for health and welfare (pp. 346-365). New Brunswick, NJ: Rutgers University Press.

Delfabbro, P., Hirte, C., Rogers, N., \& Wilson, R. (2010). The over-representation of young Aboriginal or Torres Strait Islander people in the South Australian child system: A longitudinal analysis. Children and Youth Services Review, 32, 1418-1425. https://doi. org/10.1016/j.childyouth.2010.06.011

Farrow, F., \& Schorr, L. (2011). Expanding the evidence universe: Doing better by knowing more. Washington, DC: Center for the Study of Social Policy. 
Fiester, L. (2011). Measuring change while changing measures: Learning in, and from, the evaluation of Making Connections. Baltimore, MD: The Annie E. Casey Foundation. Retrieved from http://www.aecf.org/m/resourcedoc/aecf-MeasuringChangeWhileChangingMeasures-2011.pdf

Foster-Fishman, P. G., Nowell, B., \& Yang, H. (2007). Putting the system back into systems change: A framework for understanding and changing organizational and community systems. American Journal of Community Psychology, 39(3-4), 197-215. https://doi. org/10.1007/s10464-007-9109-0. Medline:17510791

Foster-Fishman, P. G., \& Watson, E. R. (2012). The ABLe change framework: A conceptual and methodological tool for promoting systems change. American Journal of Community Psychology, 49(3-4), 503-516. https://doi.org/10.1007/s10464-011-9454-x. Medline:21735334

Gillespie, J., Supernault, G., \& Abel, M. (2014). Community networking: A promising practice for Aboriginal child welfare. In D. Badry, M. Montgomery, D. Fuchs, \& S. McKay (Eds.), Reinvesting in families, securing a brighter future: Voices from the Prairies (pp. 201-219). Edmonton, AB: Prairie Child Welfare Consortium/Alberta Centre for Child, Family and Community Research.

Hill, J. R., \& Thies, J. (2010). Program theory and logic model to address the co-occurrence of domestic violence and child maltreatment. Evaluation and Program Planning, 33(4), 356-364. https://doi.org/10.1016/j.evalprogplan.2010.03.001. Medline:20452671

Kania, J., \& Kramer, M. (2011). Collective impact. Stanford Social Innovation Review (Winter), 36-41. Retrieved from http://www.ssireview.org/articles/entry/collective_impact

Kaufman, J. S., Crusto, C. A., Quan, M., Ross, E., Friedman, S. R., O’Rielly, K., \& Call, S. (2006). Utilizing program evaluation as a strategy to promote community change: Evaluation of a comprehensive, community-based, family violence initiative. American Journal of Community Psychology, 38(3-4), 191-200. https://doi.org/10.1007/ s10464-006-9086-8. Medline:17086485

Kawakami, A., Aton, K., Cram, F., Lai, M., \& Porima, L. (2007). Improving the practice of evaluation through Indigenous values and methods: Decolonizing evaluation practice-Returning the gaze from Hawai'i and Aotearoa. Hülili: Multidisciplinary Research on Hawaiian Well-Being, 4(1), 319-348.

Kelly, T. (2010). Five simple rules for evaluating complex community initiatives. Community Investments, 22(1), 19-22. Retrieved from http://www.frbsf.org/communitydevelopment/files/Spring_CI_2010a.pdf

Kingsley, G. T., Coulton, C. J., \& Pettit, K. L. S. (2014). Strengthening communities with neighborhood data. Washington, DC: Urban Institute. Retrieved from http://www. urban.org/sites/default/files/13805_urban-kingsley.pdf

Komro, K. A., Flay, B. R., Biglan, A., \& Wagenaar, A. C. (2016). Research design issues for evaluating complex multicomponent interventions in neighborhoods and communities. Translational Behavioral Medicine, 6(1), 153-159. https://doi.org/10.1007/ s13142-015-0358-4. Medline:27012263

Kovach, M. (2009). Indigenous methodologies: Characteristics, conversations, and contexts. Toronto, ON: University of Toronto Press.

Kubisch, A., Auspos, P., Brown, P., Buck, E., \& Dewar, T. (2011). Voices from the field III: Lessons and challenges for foundations based on two decades of community-change 
efforts. The Foundation Review, 3(1), 138-149. https://doi.org/10.4087/foundationreview-d-11-00010

LaFrance, J., \& Nichols, R. (2010). Reframing evaluation: Defining an Indigenous evaluation framework. Canadian Journal of Program Evaluation, 23(2), 13-31.

Lavergne, C., Dufour, S., Trocmé, N., \& Larrivée, M. (2008). Visible minority, Aboriginal and Caucasian children investigated by Canadian child protective services. Child Welfare, 87(2), 59-76.

Lee, K. S., \& Chavis, D. M. (2012). Cross-case methodology: Bringing rigour to community and systems change research and evaluation. Journal of Community \& Applied Social Psychology, 22(5), 428-438. https://doi.org/10.1002/casp.1131

Martin, K., \& Mirraboopa, B. (2009). Ways of knowing, being and doing: A theoretical framework and methods for Indigenous and Indigenist re-search. Journal of Australian Studies, 27(76), 203-214. https://doi.org/10.1080/14443050309387838

Patton, M. Q. (2010). Developmental evaluation: Applying complexity concepts to enhance innovation and use. New York, NY: Guilford Press.

Peters, R. D., Petrunka, K., Khan, S., Howell-Moneta, A., Nelson, G., Pancer, S. M., \& Loomis, C. (2016). Cost-savings analysis of the Better Beginnings, Better Futures community-based project for young children and their families: A 10-year followup. Prevention Science, 17(2), 237-247. https://doi.org/10.1007/s11121-015-0595-2. Medline:26319616

Provan, K. G., Veazie, M. A., Staten, L. K., \& Teufel-Shone, N. I. (2005). The use of network analysis to strengthen community partnerships. Public Administration Review, 65(5), 603-613. https://doi.org/10.1111/j.1540-6210.2005.00487.x

Public Health Agency of Canada. (2010). Canadian incidence study of reported child abuse and neglect-2008: Major findings. Ottawa, ON. Retrieved from https://cwrp.ca/sites/ default/files/publications/en/CIS-2008-rprt-eng.pdf

Rogers, P. J. (2008). Using programme theory to evaluate complicated and complex aspects of interventions. Evaluation, 14(1), 29-48. https://doi.org/10.1177/1356389007084674

Royal Commission on Aboriginal Peoples. (1997). Report of the Royal Commission on Aboriginal Peoples. Volume 3: Gathering strength. Ottawa, ON: Government of Canada.

Sinha, V., Trocmé, N., Fallon, B., MacLaurin, B., Fast, E., Thomas Prokop, S., . . Kenn, R. (2011). Kiskisik Awasisak: Remember the children: Understanding the overrepresentation of First Nations children in the child welfare system. Ottawa, ON: Assembly of First Nations. Retrieved from http://cwrp.ca/sites/default/files/publications/en/ FNCIS-2008_March2012_RevisedFinal.pdf

Sridharan, S., Campbell, B., \& Zinzow, H. (2006). Developing a stakeholder-driven anticipated timeline of impact for evaluation of social programs. American Journal of Evaluation, 27(2), 148-162. https://doi.org/10.1177/1098214006287990

Thoburn, J. (2007). Globalisation and child welfare: Some lessons from a cross-national study of children in out-of-home care. Social Work Monographs. Norwich, England: UEA. Retrieved from https://www.onpe.gouv.fr/system/files/ao/j_thoburn_rapport.pdf

Torjman, S., \& Leviten-Reid, E. (2003). Comprehensive community initiatives. Ottawa, ON: Caledon Institute of Social Policy. Retrieved from http://fcssaa.org/sites/default/files/ documents/Comprehensive\%20Community\%20Initiatives,\%202003.pdf 
Trocmé, N., Knoke, D., \& Blackstock, C. (2004). Pathways to the overrepresentation of Aboriginal children in Canada's child welfare system. Social Service Review, 78(4), 577-600. https://doi.org/10.1086/424545

Tuhiwai-Smith, L. (2012). Decolonizing methodologies: Research and Indigenous peoples (2nd ed.). New York, NY: Zed Books.

U.S. Department of Health and Human Services, Administration for Children and Families, Administration on Children, Youth and Families, Children's Bureau. (2009). The AFCARS report: Preliminary estimates for FY 2008 as of October 2009 (Report \#16). Retrieved from https://www.acf.hhs.gov/sites/default/files/cb/afcarsreport16.pdf

Wilson, S. (2008). Research is ceremony: Indigenous research methods. Halifax, NS: Fernwood.

\section{AUTHOR INFORMATION}

Judy Gillespie is an associate professor with the School of Social Work at the University of British Columbia's Okanagan campus in Kelowna, BC.

Jason Albert is an associate professor with the School of Indigenous Social Work at First Nations University of Canada.

Shelaine Grant completed her Master of Social Work degree at the University of British Columbia's Okanagan campus. She is currently a clinical social worker with Island Health in Victoria, BC.

Tanya MacKeigan completed her Master of Social Work degree at the University of British Columbia's Okanagan campus. She lives in Kelowna, BC, and works in policy and community development with Okanagan Indigenous communities. 